\title{
The Frequency and Health Benefits of Physical Activity for Older Adults
}

\author{
Shirley Musich, PhD, Shaohung S. Wang, PhD, Kevin Hawkins, PhD, and Chris Greame, BBA²
}

\begin{abstract}
The benefits of physical activity (PA) for older adults have been demonstrated in reduced prevalence of common chronic conditions, improved mental health, decreased cognitive decline, and reduced mortality rates. Less is understood concerning the health impacts of light-to-moderate intensity PA. The purpose of this study was to estimate light-to-moderate PA frequency levels-low (0-2 days/week), intermediate (3-4 days/week) and high ( $\geq 5$ days/week) — among AARP Medicare Supplement insureds, identify characteristics, and estimate the association of PA levels with the prevalence of selected chronic conditions, health care utilization, and expenditures. In 2015, surveys were sent to a random sample of insureds. PA was determined from survey responses querying self-reported days per week of at least 30 minutes of light-to-moderate PA. Multivariate regression models, adjusting for confounding covariates and survey nonresponse bias, were utilized to determine the characteristics and association of intermediate and high PA levels with health outcomes. In a second analysis, results were stratified by age groups: 65-69, 70-79, and $\geq 80$ years. Among survey respondents $(n=17,676), 23.3 \%, 33.9 \%$, and $42.9 \%$ engaged in low, intermediate, and high PA, respectively. The strongest predictors of intermediate and high PA included being male, younger, self-reporting better health, using fewer prescription drugs, and being less likely to be diagnosed with common chronic conditions or depression. Those engaged in intermediate and high PA, overall and across age groups, had significantly lower health care utilization and expenditures and lower prevalence of most chronic conditions. Efforts to increase intermediate and high levels of PA among older adults should be encouraged.
\end{abstract}

\section{Introduction}

$\mathbf{T}$ HE HEALTH BENEFITS of physical activity (PA) for older adults have been well established in the scientific literature. ${ }^{1-3}$ Numerous outcomes have been studied to document associations with PA, including reduced prevalence of common chronic conditions (eg, cardiovascular disease, diabetes, hypertension), ${ }^{4-7}$ improved mental health ${ }^{8-10}$ (eg, depression, stress), quality of life, ${ }^{8-12}$ increased physical function, ${ }^{7,9,13,14}$ decreased cognitive decline $e^{15,16}$ (eg, dementia, Alzheimer's disease), and reduced mortality rates. ${ }^{6,7,17-19}$

To achieve these benefits, the Centers for Disease Control and Prevention (CDC) recommends that older adults aged 65 years and older engage in $\geq 150$ minutes of moderate intensity or $\geq 75$ minutes of vigorous intensity PA per week in addition to muscle strengthening exercises at least twice a week (for falls prevention). ${ }^{20}$ Despite the health benefits of PA in preventing disease and disability, improving physical function and mental health, as well as serving as an important preventive measure for minimizing cognitive decline, only about $40 \%$ of older adults meet the CDC guidelines for aerobic PA; only about $15 \%$ meet both the aerobic and muscle strengthening guidelines. ${ }^{21}$ This compliance rate has remained consistent since these guidelines were adopted in the United States in 2008 and among older adults in other countries that recommend US guidelines. $5,6,12,15,18,19$

Most of the scientific literature has focused on the impact of moderate and vigorous intensity PA, extending the recommendations for middle-aged adults to older adults. ${ }^{2}$ More recently, however, attention has focused on the benefits of light-to-moderate intensity PA as more likely to be adopted by older adults. ${ }^{4-6,9,11-13,16,19}$ Several studies have questioned whether the CDC guidelines should be reevaluated as too high for older adults to achieve at the population level given that, with increasing age, older adults are often limited in their capabilities for moderate or high levels of

\footnotetext{
${ }^{1}$ Advanced Analytics, Optum, Ann Arbor, Michigan.

${ }^{2}$ AARP Services, Inc., Washington, District of Columbia.
}

(C) Musich et al 2016; Published by Mary Ann Liebert, Inc. This Open Access article is distributed under the terms of the Creative Commons Attribution Noncommercial License (http://creativecommons.org/licenses/by-nc/4.0/) which permits any noncommercial use, distribution, and reproduction in any medium, provided the original author(s) and the source are credited. 
PA. 6,11,13,19,22 Among those who do engage in moderate-level PA, only about $35 \%-40 \%$ do any vigorous activity. ${ }^{5,18}$ That PA intensity decreases with age is undeniable and well documented but, to date, has not been integrated into the CDC guidelines for older adult activity. 1,11,22,23

The current aerobic guidelines of $\geq 150$ minutes of moderate PA are recommended to achieve maximum benefits across a variety of health outcomes. Fewer studies have investigated the association of PA with health care utilization and expenditures; however, consistent with disease outcomes, lower inpatient utilization and health care expenditures have been associated with increased moderate/ vigorous PA. ${ }^{24-28}$ Although the benefits of high PA levels for older adults are consistently demonstrated, the doseresponse relationship of PA with various outcomes also must be acknowledged: as PA increases (from sedentary to very active), most of the tested health outcomes likewise improve. ${ }^{4-6,8-15,18,19,24}$ Thus, although maximum benefits are generally achieved when guidelines are met, significant benefits are evident even with lower levels of PA.

Given this evidence, PA could be considered a beneficial health behavior for all but the sickest populations, promoting successful aging across a life span especially among older groups. ${ }^{29}$ The concept of effective health management of older adult populations across a continuum of health from the very healthy to the very sick has recently gained attention. ${ }^{29}$ As the populations aged 65 years and older continue to expand, understanding how best to provide quality of medical care delivery while controlling medical expenditures has become critical. ${ }^{30}$ Currently, it is estimated that about $90 \%$ of those aged 65 years and older have at least 1 chronic condition; $50 \%$ have multiple chronic conditions. ${ }^{31}$ Because these individuals often incur very high medical expenditures, many health insurance plans, including Medicare, devote considerable attention to managing current medical episodes and/or complex needs with numerous care management programs, including care coordination, case and disease management, or medication reviews. However, less attention is given to older adults who are currently healthy, either without chronic conditions or with well-managed chronic conditions. To effectively manage the health of a population, programs and services must be available to all levels of health. ${ }^{29}$ Thus, healthier segments of the population would benefit from wellness and prevention strategies and an emphasis on lifestyle behaviors (eg, PA) that could assist in keeping them as healthy as possible as they age, improving quality of life with more years spent with minimal morbidity and/or disability. ${ }^{32}$

Examinations of PA patterns and the health benefits of PA among older adults usually focus on those in various age ranges at the population level (eg, $\geq 50,{ }^{6,10,12,22,25} \geq 60,{ }^{9,19}$ or $\geq 65$ years $^{4.5,7,11,15}$ ). Medicare beneficiaries . $^{44,26,27}$ and health care expenditures ${ }^{24,26,27}$ are less often the focus of this research. To date, the authors could find no published research studies investigating the prevalence of PA levels and the association with health benefits among older adults with Medicare Supplement plans (ie, Medigap). Although most (about 90\%) of those with original fee-for-service Medicare coverage have some type of supplemental insurance coverage, about $28 \%$ (currently about 10.2 million adults) have purchased Medigap coverage. ${ }^{33}$ Because this population may differ from general older adult and/or specifically Medicare populations, it was of interest to examine their PA patterns relative to national guidelines for older adults and to detail associated characteristics and health outcomes.

Thus, the primary objective of this study was to estimate the prevalence of defined PA frequency levels among AARP Medicare Supplement insureds and determine associated characteristics. A second objective was to document the benefits of increasing PA frequency levels on (1) the prevalence of common physical and mental chronic conditions, (2) health care utilization (ie, inpatient admissions and emergency room [ER] visits), and (3) medical and prescription drug expenditures. In addition, these objectives were considered across 3 age groups $-65-69,70-79$, and $\geq 80$ yearsto better understand the benefits of PA across the life span of older adults.

\section{Methods}

\section{Sample selection}

In 2015, $\sim 4$ million Medicare insureds were covered by an AARP Medicare Supplement plan insured by UnitedHealthcare Insurance Company (for New York residents, UnitedHealthcare Insurance Company of New York). These plans are offered in all 50 states, Washington, DC, and various US territories. From September through December 2015, AARP Medicare Supplement insureds in 3 states (Missouri, New Jersey, and Washington) were randomly surveyed to screen for general health needs. To be eligible for this cross-sectional study, survey respondents were required to be at least 65 years of age, have a minimum of 3 months of AARP Medicare Supplement plan coverage pre survey completion, and have answered the PA question $(N=1169$ excluded). To minimize the possibility of limitation-related physical inactivity, those who indicated they had trouble walking and reported 0 days of PA $(N=1067)$ or were in the top $1 \%$ of medical expenditures $(N=178$; outliers) also were excluded. The final study sample included 17,676 survey respondents and was used to determine overall prevalence, characteristics, and health outcomes associated with PA. The age-related study objectives included stratification of this study sample by 3 age groups: 65-69 years $(N=5529), 70-79$ years $(N=7873)$, and $\geq 80$ years $(N=4274)$.

\section{Survey}

The general health needs survey (21 questions) was developed and validated in 2014 by UnitedHealthcare to screen for health status (eg, self-reported health status, number of prescription drugs, number of hospitalizations), physical health risks (eg, physical inactivity, difficulty with walking/balance, disabilities), mental health risks (eg, loneliness, depression, lack of social networks or support), health literacy, and willingness to participate in provided health programs.

Light-to-moderate PA levels were identified from survey responses to the following question: How many days per week do you get 30 minutes or more of light-to-moderate PA? Examples include walking, gardening, golfing, among others, with possible responses of 0-7 days per week. The survey was delivered via interactive voice response telephonic outbound calls from a designated list of 100,000 
randomly selected insureds. Three PA levels were defined from the survey responses querying weekly frequency of light-to-moderate PA: low (0-2 days per week), intermediate (3-4 days per week), and high ( $\geq 5$ days per week; aligned with $\mathrm{CDC}$ recommendations).

\section{Outcomes}

Prevalence of common chronic conditions. Nine common medical conditions used in calculating the Charlson Comorbidity Index (CCI) score $^{34}$ were defined from diagnoses codes in the health care claims: any malignancy, chronic obstructive pulmonary disease (COPD), dementia, diabetes (mild, moderate, or with chronic complications), heart problems (myocardial infarction, heart failure, peripheral vascular disease), liver disease (mild, moderate, or severe), renal disease, rheumatologic disease, or stroke. $\mathrm{CCI}$ is a measure of the risk of 1-year all-cause mortality attributable to selected comorbidities that also has been shown to be highly predictive of morbidity and health care expenditures. The validated 2-item depression questionnaire, Patient Health Questionnaire-2 (PHQ-2), was used to screen for depression. Scores of 2 and $\geq 3$ were categorized as subthreshold depression and depression, respectively. ${ }^{35}$

Health care utilization and expenditures. Health care utilization was defined from medical claims as an inpatient admission or ER visit within 1 year pre survey completion. Health care utilization is shown as an annual rate percentage. Health care expenditures were defined as paid claims per member per month (PMPM) US dollars from the same time period aggregated from Medicare, Medicare Supplement, and patient out-of-pocket paid amounts. Prescription drug expenditures included AARP Medicare Rx paid claims and patient co-payments for those also enrolled in an AARP Medicare Part D prescription drug plan, insured by UnitedHealthcare: $N=9474 ; 54 \%$ of the overall sample.

Covariates. Covariates were included to characterize PA levels and to adjust for factors that may influence the prevalence of chronic conditions, health care utilization, and expenditures. These covariates included measures of demographics, socioeconomic factors, health status, and other characteristics taken from health plan eligibility and administrative medical claims.

Demographics. Demographic questions included age and sex. Age groups were defined as 64-69, 70-79, $\geq 80$ years. Living in urban and other locations and high, medium, or low minority areas were geocoded from zip codes. AARP Medicare Supplement plan types were grouped by cost-sharing levels, including high-level coverage plans with no co-payments or deductibles (plans $\mathrm{C}, \mathrm{F}$, and J), mediumlevel coverage (plans B, D, E, G, H, I, and N) and low-level coverage (plans $\mathrm{A}, \mathrm{K}$, and $\mathrm{L}$ ). Other survey covariates included caregiver status, need to stay at home, family/friend social support status, number included in social networks, and willingness to participate in health programs.

Loneliness score. Loneliness was measured using the validated University of California-Los Angeles (UCLA) 3-item scale with responses never/hardly ever, some of the time, and often. ${ }^{36}$ The questions were scored $1-3$ and then summed to a score ranging from 3 to 9 . Loneliness was subsequently categorized as no loneliness (score $=3$ ), moderate loneliness (score $=4$ or 5 ), and severe loneliness $($ score $=6-9$ ).

Self-reported number of prescription drugs. The number of prescription drugs taken by the individual was selfreported on the survey as a continuous variable: how many different prescription drugs do you take each day? The number of prescription drugs was subsequently categorized as 0 prescription drugs, 1-3 prescription drugs, 4-6 prescription drugs, or $\geq 7$ prescription drugs.

Health literacy. Health literacy was measured with the single validated question asking for confidence level in filling out medical forms. ${ }^{37}$ The demographic, socioeconomic, and health status covariates considered are listed in Table 1.

\section{Statistical models}

Propensity weighting was used to adjust for potential selection bias often associated with survey response to enhance the generalizability of these findings. The propensity weighting utilized available information about the aforementioned demographic, socioeconomic, and health status variables that could potentially influence survey response. This information was used to estimate the underlying probability of survey response for each individual. That estimated probability was then used to create and apply a weighting variable to the data to make those who did respond better resemble all eligible insureds who received the survey. The utility of such propensity weighting models to adjust for external validity threats is described elsewhere. $^{38,39}$

Characteristics associated with PA frequency levels were determined using multivariate logistic regression models for high and intermediate versus low levels of PA weighted to adjust for survey nonresponse. Covariates included all of those variables listed in Table 1. The prevalence of common physical and mental medical conditions was determined and regression adjusted for low, intermediate, and high PA levels (overall and by age subgroups). Health care utilization (inpatient admissions and ER visits) and health care expenditures (medical and prescription drugs) for low, intermediate, and high PA levels (overall sample and by age subgroups) were determined and regression adjusted for demographic, socioeconomic, and survey response variables.

\section{Results}

Overall, 20,211 AARP Medicare Supplement insureds in the 3 states responded to the survey (20.2\% response rate). Of these, 17,676 (87.5\%) met the eligibility criteria and were included in the study. Survey respondents were mostly female, 70-79 years of age, white (low minority), and reported much better health than others. Among survey respondents, the prevalence of low, intermediate, and high PA levels was $23.3 \%, 33.9 \%$, and $42.9 \%$, respectively (Table 1 ). 
Table 1. Unadjusted Demographic Characteristics of Physical Activity Frequency Levels

\begin{tabular}{|c|c|c|c|c|c|}
\hline & $\begin{array}{c}\text { All \% } \\
\text { or mean }\end{array}$ & $\begin{array}{l}\text { PA low \% } \\
\text { or mean }\end{array}$ & $\begin{array}{l}\text { PA intermediate } \\
\% \text { or mean }\end{array}$ & $\begin{array}{l}\text { PA high \% } \\
\text { or mean }\end{array}$ & $\mathrm{P}$ \\
\hline Number & 17,676 & 4114 & 5986 & 7576 & \\
\hline \multicolumn{6}{|l|}{ Sex } \\
\hline Male & 34.3 & 30.0 & 33.5 & 37.2 & \multirow{2}{*}{$<0.0001$} \\
\hline Female & 65.7 & 70.0 & 66.5 & 62.8 & \\
\hline Age groups, years & 74.5 & 75.8 & 74.4 & 73.9 & \multirow{4}{*}{$\begin{array}{l}<0.0001 \\
<0.0001\end{array}$} \\
\hline $65-69$ & 31.3 & 26.3 & 31.8 & 33.6 & \\
\hline $70-79$ & 44.5 & 42.1 & 44.9 & 45.6 & \\
\hline$\geq 80$ & 24.2 & 31.5 & 23.3 & 20.9 & \\
\hline \multicolumn{6}{|l|}{ Minority status (geocoded) } \\
\hline Low & 58.2 & 54.6 & 57.9 & 60.3 & \multirow[t]{3}{*}{$<0.0001$} \\
\hline Medium & 38.5 & 41.8 & 38.8 & 36.5 & \\
\hline High & 2.6 & 3.0 & 2.7 & 2.4 & \\
\hline \multicolumn{6}{|l|}{ Self-rated physical health } \\
\hline Much better & 40.7 & 24.3 & 38.7 & 51.3 & \multirow[t]{5}{*}{$<0.0001$} \\
\hline Slightly better & 24.4 & 23.5 & 26.3 & 23.5 & \\
\hline About the same & 26.0 & 35.8 & 27.6 & 19.5 & \\
\hline Slightly worse & 6.6 & 12.3 & 5.8 & 4.0 & \\
\hline Much worse & 1.2 & 2.8 & 0.8 & 0.7 & \\
\hline \multicolumn{6}{|l|}{ PA days/week } \\
\hline 0 & 5.1 & 21.9 & & & \multirow{8}{*}{$<0.0001$} \\
\hline 1 & 6.7 & 28.9 & & & \\
\hline 2 & 11.5 & 49.2 & & & \\
\hline 3 & 20.3 & & 59.9 & & \\
\hline 4 & 13.6 & & 40.1 & & \\
\hline 5 & 18.6 & & & 43.4 & \\
\hline 6 & 6.7 & & & 15.7 & \\
\hline 7 & 17.5 & & & 40.9 & \\
\hline \multicolumn{6}{|l|}{ UCLA-3 Loneliness Scale } \\
\hline 3 (Never/Hardly ever) & 69.2 & 60.1 & 69.0 & 74.2 & \multirow{3}{*}{$<0.0001$} \\
\hline 4-5 (Moderate) & 19.8 & 23.0 & 20.8 & 17.3 & \\
\hline \multirow{2}{*}{\multicolumn{6}{|c|}{ Family social support }} \\
\hline & & & & & \\
\hline Often & 74.7 & 69.2 & 74.9 & 77.5 & \multirow[t]{4}{*}{$<0.0001$} \\
\hline Some of the time & 15.5 & 19.0 & 15.9 & 13.3 & \\
\hline Hardly ever & 4.6 & 5.0 & 4.7 & 4.3 & \\
\hline Never & 2.3 & 2.3 & 2.0 & 2.6 & \\
\hline \multicolumn{6}{|l|}{ Social network (No.) } \\
\hline 0 & 2.9 & 3.0 & 2.4 & 3.2 & $<0.0001$ \\
\hline $1-2$ & 12.5 & 18.5 & 11.8 & 9.8 & \\
\hline $3-4$ & 25.4 & 27.2 & 27.0 & 23.1 & \\
\hline$\geq 5$ & 56.0 & 46.4 & 55.9 & 61.4 & \\
\hline Caregiver & & & & & \\
\hline Yes & 14.6 & 13.6 & 13.6 & 15.9 & $<0.0001$ \\
\hline Need to stay in the hous & & & & & \\
\hline Yes & 6.5 & 13.6 & 4.9 & 3.9 & $<0.0001$ \\
\hline No. of prescription drugs & & & & & \\
\hline 0 & 8.4 & 3.9 & 7.7 & 11.4 & $<0.0001$ \\
\hline $1-3$ & 39.6 & 29.3 & 39.7 & 45.1 & \\
\hline $4-6$ & 34.6 & 40.8 & 36.2 & 30.0 & \\
\hline$\geq 7$ & 12.2 & 18.6 & 11.7 & 9.1 & \\
\hline PHQ-2 Score & & & & & \\
\hline 0 & 75.3 & 64.3 & 75.4 & 81.3 & $<0.0001$ \\
\hline 1 & 9.3 & 11.7 & 10.1 & 7.5 & \\
\hline 2 & 5.7 & 8.3 & 6.0 & 4.0 & \\
\hline$\geq 3$ & 4.8 & 8.6 & 4.2 & 3.3 & \\
\hline Participate in health pros & & & & & \\
\hline Yes & 34.4 & 31.6 & 36.1 & 34.6 & $<0.0001$ \\
\hline Health literacy & & & & & \\
\hline Not at all confident & 2.3 & 3.8 & 1.9 & 1.7 & $<0.0001$ \\
\hline A little bit confident & 3.0 & 4.1 & 2.9 & 2.5 & \\
\hline Somewhat confident & 8.7 & 10.7 & 9.2 & 7.3 & \\
\hline Quite confident & 18.2 & 19.0 & 19.1 & 17.0 & \\
\hline Extremely confident & 57.8 & 49.8 & 57.2 & 62.6 & \\
\hline
\end{tabular}

Missing, state of residence, urban/rural location, and health plan types also were included as covariates but not shown for brevity.

PA, physical activity; PHQ-2, Patient Health Questionnaire-2 (2-item depression screen); UCLA-3 Loneliness Scale, University of California-Los Angeles-3 item Loneliness Scale. 
Table 2. Characteristics of Those Engaged in High Frequency Physical Activity Compared to Low Activity

\begin{tabular}{|c|c|c|}
\hline Variable & Odds ratio & $\mathrm{P}$ \\
\hline \multicolumn{3}{|l|}{ High physical activity vs. low } \\
\hline Health much better & 3.14 & $<0.0001$ \\
\hline Health slightly better & 1.65 & $<0.0001$ \\
\hline High health literacy & 1.28 & $<0.0001$ \\
\hline Low minority (white) & 1.20 & $<0.0001$ \\
\hline Participate in health programs & 1.19 & $<0.0001$ \\
\hline Caregiver & 1.12 & $<0.0001$ \\
\hline 1-3 Prescription drugs & 1.08 & 0.01 \\
\hline Moderate loneliness & 0.89 & $<0.0001$ \\
\hline Some family support & 0.88 & $<0.0001$ \\
\hline Age $70-79$ years & 0.86 & $<0.0001$ \\
\hline Renal disease & 0.84 & $<0.0001$ \\
\hline Dementia & 0.83 & 0.002 \\
\hline COPD & 0.81 & $<0.0001$ \\
\hline Severe loneliness & 0.79 & $<0.0001$ \\
\hline 4-6 Prescription drugs & 0.76 & $<0.0001$ \\
\hline $\begin{array}{l}\text { PHQ-2 = } 2 \text { (subthreshold } \\
\text { depression) }\end{array}$ & 0.75 & $<0.0001$ \\
\hline PHQ-2 = $\geq 3$ (depression) & 0.73 & $<0.0001$ \\
\hline$\geq 7$ Prescription drugs & 0.72 & $<0.0001$ \\
\hline Liver disease & 0.72 & $<0.0001$ \\
\hline Female & 0.67 & $<0.0001$ \\
\hline Diabetes & 0.65 & $<0.0001$ \\
\hline Age $\geq 80$ years & 0.61 & $<0.0001$ \\
\hline Need to stay in house & 0.52 & $<0.0001$ \\
\hline
\end{tabular}

COPD, chronic obstructive pulmonary disease; PHQ-2, Patient Health Questionnaire-2 (2-item depression screen).

\section{Characteristics associated with PA frequency levels: high and intermediate versus low}

The strongest characteristic of high and intermediate PA frequency levels was self-reported better health (Tables 2 and 3). Other characteristics associated with high and intermediate PA levels included being male, younger $(<70$ years), white (low minority), using fewer prescription drugs, and being less likely to be diagnosed with common physical (ie, diabetes, renal disease, liver disease, COPD) and mental (ie, dementia, depression) medical conditions.

\section{Association of PA frequency levels with prevalence of common physical and mental conditions}

There was a significant association of PA frequency with the reduced prevalence of 6 of the 9 common physical and mental conditions measured. COPD, diabetes, heart problems, and renal disease showed dose-response relationships with significantly lower prevalence as PA increased (Table 4). For dementia and liver disease, only high levels of PA significantly reduced the prevalence of these conditions. Depression, measured from the PHQ-2, was lower for those with high or intermediate PA compared to those with low PA.

Across age groups, PA frequency was associated with each of these physical and/or mental medical conditions, although relationships varied by disease. The prevalence of diabetes showed the strongest dose-response relationship with PA frequency across all 3 age groups; as PA increased,
Table 3. Characteristics of Those Engaged In Intermediate Frequency Physical Activity COMPARED to Low ACTIVITY

\begin{tabular}{lcc}
\hline Variable & Odds ratio & $\mathrm{P}$ \\
\hline Intermediate physical activity vs. low & \\
Health much better & 1.89 & $<0.0001$ \\
Health slightly better & 1.40 & $<0.0001$ \\
Intend to participate in & 1.25 & $<0.0001$ \\
$\quad$ health programs & & \\
1-3 Prescription drugs & 1.19 & $<0.0001$ \\
High health literacy & 1.15 & $<0.0001$ \\
White & 1.08 & $<0.0001$ \\
PHQ-2=2 (subthreshold & 0.92 & 0.04 \\
depression) & & \\
Age 70-79 years & 0.88 & $<0.0001$ \\
Severe loneliness & 0.86 & $<0.0001$ \\
Renal disease & 0.85 & $<0.0001$ \\
$\geq 7$ Prescription drugs & 0.85 & $<0.0001$ \\
COPD & 0.83 & $<0.0001$ \\
Female & 0.82 & $<0.0001$ \\
Diabetes & 0.82 & $<0.0001$ \\
PHQ-2= $\geq 3$ (depression) & 0.73 & $<0.0001$ \\
Age $\geq 80$ years & 0.68 & $<0.0001$ \\
Need to stay in house & 0.51 & $<0.0001$ \\
\hline
\end{tabular}

COPD, chronic obstructive pulmonary disease; PHQ-2, Patient Health Questionnaire-2 (2-item depression screen).

diabetes significantly decreased. Reduced dementia was most strongly related to high PA for all age groups. Depression was lower with both intermediate and high PA for those aged 65-69 and 70-79 years but only lower for high PA for those aged $\geq 80$ years.

\section{Association of PA frequency levels with health care utilization and expenditures}

There was a dose-response relationship for health care utilization for inpatient admissions and ER visits (all level comparisons significant) across all PA frequency levels (Table 5). A similar dose-response relationship was evident for paid medical and drug expenditures (all level comparisons significant): as PA frequency increased, medical and drug expenditures significantly decreased (Table 5 and Fig. 1). High levels of PA demonstrated the largest association with utilization and expenditures compared to low levels (inpatient admissions $-4.0 \%$; ER $-3.7 \%$; medical expenditures -\$201 PMPM; prescription drug expenditures -\$78 PMPM). Intermediate levels of PA were associated with significantly lower utilization and expenditures compared to low PA but were not as impactful as high PA levels (inpatient admissions $-2.4 \%$; ER $-1.4 \%$; medical expenditures -\$118 PMPM; prescription drug expenditures $-\$ 45$ PMPM). Similar dose-response relationships for high and intermediate PA frequency levels with health care utilization and expenditures held across age groups 65-69 and 70-79 years but generally were not significant for those aged $\geq 80$ years (with the exception of inpatient admissions).

\section{Discussion}

In this study's population of AARP Medicare Supplement insureds, $23.3 \%, 33.9 \%$, and $42.9 \%$ were engaged in low, 
Table 4. Regression Adjusted Prevalence of Chronic Conditions Associated with Physical Activity Frequency Levels Overall and by Age Groups

\begin{tabular}{|c|c|c|c|c|c|c|}
\hline & \multicolumn{3}{|c|}{ Physical activity levels } & \multicolumn{3}{|c|}{$\mathrm{P}$} \\
\hline & $\begin{array}{c}\text { Low }(L) \\
(\%)\end{array}$ & $\begin{array}{l}\text { Intermediate } \\
\quad(I)(\%)\end{array}$ & $\begin{array}{c}\operatorname{High}(H) \\
(\%)\end{array}$ & $H$ vs. $L$ & $M$ vs. $L$ & $H$ vs. $M$ \\
\hline \multicolumn{7}{|l|}{ All ages } \\
\hline COPD & 19.7 & 17.2 & 16.6 & $<0.0001$ & $<0.0001$ & 0.07 \\
\hline Dementia & 2.5 & 2.4 & 2.1 & 0.0006 & 0.24 & 0.02 \\
\hline Diabetes & 23.0 & 19.9 & 16.7 & $<0.0001$ & $<0.0001$ & $<0.0001$ \\
\hline Heart problem & 20.0 & 19.0 & 18.4 & $<0.0001$ & 0.001 & 0.08 \\
\hline Liver disease & 2.3 & 2.4 & 1.6 & $<0.0001$ & 0.91 & $<0.0001$ \\
\hline PHQ-2 $\geq 3$ (depression) & 5.8 & 4.4 & 4.4 & $<0.0001$ & $<0.0001$ & 0.82 \\
\hline Renal disease & 11.0 & 9.2 & 8.8 & $<0.0001$ & $<0.0001$ & 0.04 \\
\hline \multicolumn{7}{|l|}{ COPD, years } \\
\hline $65-69$ & 17.0 & 15.0 & 14.0 & $<0.0001$ & 0.000 & 0.04 \\
\hline $70-79$ & 19.9 & 18.6 & 17.5 & $<0.0001$ & 0.01 & 0.02 \\
\hline$\geq 80$ & 22.1 & 17.2 & 18.1 & $<0.0001$ & $<0.0001$ & 0.12 \\
\hline \multicolumn{7}{|l|}{ Dementia, years } \\
\hline $65-69$ & 1.3 & 0.8 & 0.7 & $<0.0001$ & 0.003 & 0.12 \\
\hline $70-79$ & 1.9 & 1.9 & 2.3 & 0.03 & 0.69 & 0.06 \\
\hline$\geq 80$ & 4.9 & 4.8 & 3.4 & $<0.0001$ & 0.86 & $<0.0001$ \\
\hline \multicolumn{7}{|l|}{ Diabetes, years } \\
\hline $65-69$ & 23.1 & 19.7 & 16.9 & $<0.0001$ & $<0.0001$ & $<0.0001$ \\
\hline $70-79$ & 23.7 & 20.0 & 17.2 & $<0.0001$ & $<0.0001$ & $<0.0001$ \\
\hline$\geq 80$ & 21.6 & 19.8 & 15.3 & $<0.0001$ & 0.005 & $<0.0001$ \\
\hline \multicolumn{7}{|l|}{ Heart problems, years } \\
\hline $65-69$ & 12.8 & 11.6 & 11.1 & $<0.0001$ & 0.02 & 0.21 \\
\hline $70-79$ & 18.2 & 18.0 & 17.9 & 0.61 & 0.79 & 0.79 \\
\hline$\geq 80$ & 31.9 & 29.6 & 28.3 & $<0.0001$ & 0.002 & 0.07 \\
\hline \multicolumn{7}{|l|}{ Liver disease, years } \\
\hline $65-69$ & 3.1 & 3.7 & 2.4 & 0.01 & 0.04 & $<0.0001$ \\
\hline $70-79$ & 2.9 & 2.1 & 1.6 & $<0.0001$ & $<0.0001$ & 0.006 \\
\hline$\geq 80$ & 0.6 & 1.3 & 0.7 & 0.42 & 0.000 & 0.002 \\
\hline \multicolumn{7}{|c|}{ PHQ-2 $\geq 3$ (depression), years } \\
\hline $65-69$ & 5.9 & 4.4 & 4.2 & $<0.0001$ & $<0.0001$ & 0.52 \\
\hline $70-79$ & 6.1 & 4.0 & 4.5 & $<0.0001$ & $<0.0001$ & 0.02 \\
\hline$\geq 80$ & 5.4 & 5.1 & 4.4 & 0.0005 & 0.32 & 0.02 \\
\hline \multicolumn{7}{|l|}{ Renal disease, years } \\
\hline $65-69$ & 6.8 & 6.5 & 4.5 & $<0.0001$ & 0.53 & $<0.0001$ \\
\hline $70-79$ & 11.0 & 8.4 & 8.7 & $<0.0001$ & $<0.0001$ & 0.37 \\
\hline$\geq 80$ & 16.1 & 13.7 & 14.1 & 0.001 & $<0.0001$ & 0.53 \\
\hline
\end{tabular}

All ages, $N=17,676 ; 65-69$ years, $N=5529 ; 70-79$ years, $N=7873 ; \geq 80$ years, $N=4274$.

COPD, chronic obstructive pulmonary disease; PHQ-2, Patient Health Questionnaire-2 (2-item depression screen).

intermediate, and high frequency levels of light-to-moderate PA, respectively. The prevalence of high PA (defined as $\geq 5$ days per week of at least 30 minutes of PA) meets the CDC guidelines $^{20}$ for older adults for $\geq 150$ minutes of moderate PA per week. This compliance rate is in general agreement with benchmarks for those meeting aerobic recommendations published in the National Interview Survey Report (2012) for light-to-moderate PA: 39\% of older adults aged $\geq 65$ years with Medicare private insurance. ${ }^{21}$ However, compliance rates with US CDC guidelines among older adult populations in the United States as well as in other countries, regardless of precise older age groups $(\geq 50, \geq 60$, or $\geq 65$ years), generally range from $35 \%$ to $45 \% .^{5,12,18,22,23}$ Overall, those engaged in intermediate and high frequency levels of PA in this study population were more often male, younger, white, healthier, taking fewer prescription drugs, and had a lower prevalence of common chronic conditions and depression, consistent with other studies. ${ }^{1,22,23}$ As expected, high levels of PA steadily decreased across age groups: 65-69 years, 46.0\%; 70-79 years, 43.9\%; and $\geq 80$ years, $37.0 \%$.

The strongest predictors of intermediate and high frequency levels of PA were self-reported slightly better or much better health status. Also supporting this assessment of physical health were lower probabilities for diagnosed diabetes, renal disease, dementia, COPD, and liver disease, as well as self-reported lower numbers of prescription drugs. Those engaged in higher levels of PA also were characterized by better mental health, including lower depression and loneliness, more family support, and being less likely to stay in their house. These characteristics reflect well-documented associations of PA among older adults with physical, mental, and social health and well-being. ${ }^{1-3,16,22,23}$

In cross-sectional study designs such as this, the question arises whether older adults are more physically active because they are healthier or they are healthier because they 
Table 5. Regression Adjusted Health Care Utilization and Expenditures Associated with Physical Activity Frequency Levels Overall and by Age Group

\begin{tabular}{|c|c|c|c|c|c|c|}
\hline & \multicolumn{3}{|c|}{ Physical activity levels } & \multicolumn{3}{|c|}{$\mathrm{P}$} \\
\hline & $\begin{array}{l}\text { Low }(L) \\
\% \text { or } \$\end{array}$ & $\begin{array}{l}\text { Intermediate } \\
\text { (I) } \% \text { or } \$\end{array}$ & $\begin{array}{c}\text { High }(H) \\
\% \text { or } \$\end{array}$ & $H$ vs. $L$ & $M$ vs. $L$ & $H$ vs. $M$ \\
\hline \multicolumn{7}{|l|}{ All ages } \\
\hline IP admissions (\%; annual rate) & 15.8 & 13.4 & 11.8 & $<0.0001$ & $<0.0001$ & $<0.0001$ \\
\hline ER (\%; annual rate) & 28.3 & 26.9 & 24.6 & $<0.0001$ & 0.001 & $<0.0001$ \\
\hline Medical expenditures (\$; PMPM) & 931 & 814 & 730 & $<0.0001$ & $<0.0001$ & $<0.0001$ \\
\hline Rx expenditures (\$; PMPM) & 268 & 223 & 190 & $<0.0001$ & $<0.0001$ & $<0.0001$ \\
\hline \multicolumn{7}{|l|}{ IP admissions ( $\%$; annual rate), years } \\
\hline $65-69$ & 14.9 & 11.4 & 9.2 & $<0.0001$ & $<0.0001$ & $<0.0001$ \\
\hline $70-79$ & 15.5 & 13.0 & 11.8 & $<0.0001$ & $<0.0001$ & 0.001 \\
\hline$\geq 80$ & 18.0 & 16.7 & 15.3 & $<0.0001$ & 0.05 & 0.02 \\
\hline \multicolumn{7}{|l|}{ ER visits (\%; annual rate), years } \\
\hline $65-69$ & 24.5 & 24.3 & 19.6 & $<0.0001$ & 0.74 & $<0.0001$ \\
\hline $70-79$ & 28.5 & 25.5 & 23.5 & $<0.0001$ & $<0.0001$ & $<0.0001$ \\
\hline$\geq 80$ & 33.4 & 32.6 & 33.2 & 0.79 & 0.34 & 0.47 \\
\hline \multicolumn{7}{|l|}{ Medical expenditures (\$; PMPM), years } \\
\hline $65-69$ & 862 & 737 & 615 & $<0.0001$ & 0.002 & $<0.0001$ \\
\hline $70-79$ & 982 & 822 & 755 & $<0.0001$ & $<0.0001$ & 0.02 \\
\hline$\geq 80$ & 943 & 886 & 850 & 0.05 & 0.25 & 0.42 \\
\hline \multicolumn{7}{|l|}{ Rx expenditures (\$; PMPM), years } \\
\hline $65-69$ & 344 & 232 & 170 & $<0.0001$ & $<0.0001$ & $<0.0001$ \\
\hline $70-79$ & 272 & 229 & 215 & $<0.0001$ & 0.001 & 0.17 \\
\hline$\geq 80$ & 195 & 199 & 176 & 0.15 & 0.77 & 0.08 \\
\hline
\end{tabular}

All ages, $N=17,676$; 65-69 years, $N=5529 ; 70-79$ years, $N=7873$; $\geq 80$ years, $N=4274$; AARP Medicare Part D plans, $N=9474$. ER, emergency room; IP, inpatient; PMPM, per member per month; Rx, prescription.

are more physically active. The PA scientific literature has resolved this issue with many of the health outcomes with 9- to 13-year prospective studies, ${ }^{4,7,14,16,17}$ in which older adults with similar characteristics at baseline are followed with periodic assessments over time. In these studies, those who remained physically active benefited with lower cardiovascular disease, ${ }^{4}$ better physical function and balance, ${ }^{14}$ reduced cognitive decline, ${ }^{16}$ and decreased mortality rates. ${ }^{7,17}$ So although this study can only report associations

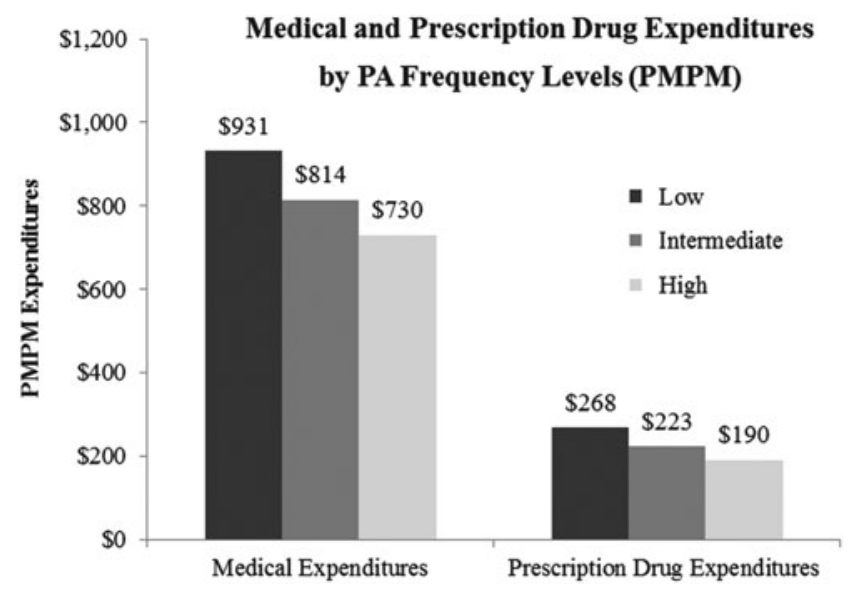

FIG. 1. Regression-adjusted medical and prescription drug expenditures among AARP Medicare Supplement insureds. Note: All comparisons significant $P<0.001$. PA, physical activity; PMPM, per member per month. of PA with improved health outcomes, the supporting literature would indicate that although some may be active because of better health, PA is also an important preventive strategy associated with positive health outcomes over time. Furthermore, evidence on study populations stratified on disabilities or limitations of various descriptions indicates that older adults with limitations continue to be physically active at rates only slightly reduced from those with no limitations, even if the type of activity may change. ${ }^{22}$

In this study population, diabetes was associated with the strongest dose-response relationship with frequency levels of PA of the chronic conditions tested, overall and across age groups (Table 4). Heart problems were related to PA levels but not as strongly and only for intermediate and high PA versus low levels. The expectation for a strong association of PA with heart disease may be a reflection that many of the published cardiovascular/PA studies have been completed among middle-aged adults rather than older adults. ${ }^{4,5}$ In agreement with other studies, lower prevalence rates for dementia were associated primarily with high levels of PA (overall and for 65-69 and $\geq 80$ age groups). ${ }^{15,16}$ In contrast, any amount of PA beyond low levels apparently reduced the prevalence of depression for all ages.

Few PA studies associated with Medicare populations have utilized administrative medical and prescription drug claims data ${ }^{24,26,27}$; to date, none with Medicare Supplement insureds. In the present study, inpatient admissions and ER visits were associated with a significant dose-response relationship across PA frequency levels. Similarly, medical and prescription drug expenditures also were associated with a strong dose-response relationship across PA levels 
(all comparison levels statistically different; Table 5 and Fig. 1): as PA levels increased, medical and prescription drug expenditures decreased. This relationship held for all but the group aged $\geq 80$ years, for whom only inpatient admissions and medical expenditures were significantly reduced for intermediate and high (inpatient admissions) or high (medical expenditures) levels of PA.

Annualized differences for medical expenditures between low PA and intermediate or high PA frequency levels indicated \$1415 and \$2418 lower paid expenditures, respectively. The magnitude of these differences is consistent with other published research studies. In a similar cross-sectional study, Wang et $\mathrm{al}^{24}$ measured levels of vigorous PA days per week in a population of Medicare retirees and demonstrated $\$ 1690$ and $\$ 2686$ lower incurred medical expenditures between low PA and intermediate and high levels, respectively. Three longitudinal research studies, measuring changes in medical expenditures with changes in PA from sedentary/low to high levels of PA over 1- to 2-year time periods, indicated reductions in medical expenditures ranging from \$1252 to \$3196 associated with increased PA. ${ }^{25-27}$ Although health benefits and improved quality of life continue to be the focus of many PA studies, the medical expenditure benefits are noteworthy.

The relationship of PA with the various outcomes is remarkably robust. There is little consistency in PA metrics in the literature with various questions utilized and intensity levels queried (eg, light, moderate, light-to-moderate, moderate-to-vigorous, vigorous) and even less consistency in the definition and numbers of levels defined (eg, active/ nonactive; recommended, insufficiently active, inactive; low, intermediate, and high, $<150$ minutes, $\geq 150$ minutes). ${ }^{1,6,11,22}$ Most often, PA is self-reported; however, accelerometers and pedometers also have been used to objectively measure PA intensities and frequency levels. ${ }^{4,9,13}$ Yet, despite the differences in metrics across studies, the characteristic doseresponse relationship for PA is generally evident regardless of the health outcome chosen. ${ }^{4-6,9,11-13,19}$

In a review of PA interventions, ${ }^{2}$ older adults generally responded to similar PA programs (eg, classes, fitness centers) ${ }^{2,26,27}$ and technologies (eg, pedometers ${ }^{40}$ ) used for younger and middle-aged adults. If there are differences, older adults may be more conscientious in attendance in multiweek interventions. ${ }^{2}$ However, once programs ended, the benefits of increased PA tended to dissipate relatively quickly. ${ }^{2,7,40}$ Nevertheless, if $\$ 1500$ to $\$ 2000$ could be realized by engaging more individuals in higher levels of PA, funding for interventions or public health messaging should be possible. Other general strategies to increase PA in older populations have focused on built environments (eg, walkable cities), health education (promoting positive messaging), and recommendations from health professionals (especially physicians) in assessing and increasing awareness of the importance and benefits to older adults. ${ }^{7}$

This study population of AARP Medicare Supplement insureds may not generalize to all older adults or other Medicare Supplement beneficiaries. Although the survey was adjusted for nonresponse, the response rate at $20 \%$ was relatively low and included insureds in only 3 states. The PA question queried self-reported days per week of light-tomoderate PA, although much of the PA literature focuses on moderate-to-vigorous PA. Although this study's results are consistent with those findings, individual interpretations of light or moderate activity may lead to some misclassification (ie, over- or underestimating PA frequency levels). Given the consistent dose-response relationships across several outcomes evident in the present study findings, the authors consider this limitation to be minimal. Strengths of the study include a relatively large study population assessing light-to-moderate activity levels, which may be more appropriate for older adults, and uniquely incorporating administrative medical and prescription drug claims data augmenting the self-reported survey results.

\section{Conclusions}

Overall, about $78 \%$ of the AARP Medicare Supplement insured study population was engaged in intermediate or high levels of light-to-moderate PA; however, only $42.9 \%$ met CDC PA guidelines. The strongest predictors of intermediate or high frequency levels of PA included being male, younger, self-reporting better health, taking fewer prescription drugs, and being less likely to be diagnosed with common chronic conditions or depression. Those engaged in intermediate or high levels of PA generally had lower prevalence of common chronic conditions, significantly lower utilization of inpatient admissions and ER visits, and significantly lower medical and prescription drug expenditures. The benefits of recommended levels of PA are evident; however, the strong dose-response relationship of PA with health outcomes would indicate, especially for older adults, that PA of all levels and intensities is beneficial. The adaptability of various types of PA to older adults' ranges of physical capabilities recommends the behavior as a consideration in population health management strategies. Increased levels of PA across all older age groups have the potential for numerous health benefits and should be encouraged.

\section{Author Disclosure Statement}

The authors declared no conflicts of interest with respect to the research, authorship, and/or publication of this article. The authors received no financial support for the research, authorship, and/or publication of this article.

\section{References}

1. Sun F, Norman IJ, White AE. Physical activity in older people: a systematic review. BMC Public Health 2013; 13:449.

2. Taylor AH, Cable NT, Faulkner G, Hillsdon M, Narici M, Van Der Bij AK. Physical activity and older adults: a review of health benefits and the effectiveness of interventions. J Sports Sci 2004;22:703-725.

3. Prakash RS, Voss MW, Erickson KI, Kramer AF. Physical activity and cognitive vitality. Annu Rev Psychol 2015;66: 769-797.

4. Soares-Miranda L, Siscovick DS, Psaty BM, Longstreth WT, Mozaffarian D. Physical activity and risk of coronary heart disease and stroke in older adults. The Cardiovascular Health Study. Circulation 2016;133:147-155.

5. Lacey B, Golledge J, Yeap BB, et al. Physical activity and vascular disease in a prospective cohort study of older men: the Health in Men Study (HIMS). BMC Geriatr 2015;15: 164. 
6. Hamer M, de Oliveira C, Demakakos P. Non-exercise physical activity and survival. Am J Prev Med 2014;47: 452-460.

7. Almeida OP, Khan KM, Hankey GJ, Yeap BB, Golledge J, Flicker L. 150 Minutes of vigorous physical activity per week predicts survival and successful aging: a populationbased 11-year longitudinal study of 12,201 older Australian men. Br J Sports Med 2014;48:220-225.

8. Mummery K, Schofield G, Caperchione C. Physical activity dose-response effects on mental health status in older adults. Aust N Z J Public Health 2004;28:188-192.

9. Varma VR, Tan EJ, Wang T, et al. Low-intensity walking activity is associated with better health. J Appl Gerontol 2014;33:870-887.

10. Becofsky K, Baruth M, Wilcox S. Physical activity mediates the relationship between program participation and improved mental health in older adults. Public Health 2016; 132:64-71.

11. Brown DR, Carroll DD, Workman LM, Carlson SA, Brown DW. Physical activity and health-related quality of life: US adults with and without limitations. Qual Life Res 2014;23: 2673-2680.

12. Heesch KC, van Uffelen JG, van Gellecum YR, Brown WJ. Dose-response relationships between physical activity, walking and health-related quality of life in mid-age and older women. J Epidemiol Community Health 2012;66:670-677.

13. Loprinzi PD, Brosky JA. Objectively measured physical activity and balance among US adults. J Strength Cond Res 2014;28:2290-2298.

14. Hillsdon MM, Brunner EJ, Guralnik JM, Marmot MG. Prospective study of physical activity and physical function in early old age. Am J Prev Med 2005;28:245-250.

15. Laurin D, Verreauli R, Lindsay J, MacPherson K, Rockwood K. Physical activity and risk of cognitive impairment and dementia in elderly persons. Arch Neurol 2001;58: 498-504.

16. Sofi F, Valecchi D, Bacci D, et al. Physical activity and risk of cognitive decline: a meta-analysis of prospective studies. J Intern Med 2011;269:107-117.

17. Nagai M, Kuriyama S, Kakizaki $M$, et al. Impact of walking on life expectance and lifetime medical expenditure: the Ohsaki Cohort Study. BMJ Open 2011;1:e000240.

18. Gebel K, Ding D, Chey T, Stanatakis E, Brown WJ, Bauman AE. Effect of moderate to vigorous physical activity on all-cause mortality in -age and older Australians. JAMA Intern Med 2015;175:970-977.

19. Hupin D, Roche F, Gremeaux V, et al. Even a low-dose of moderate-to-vigorous physical activity reduces mortality by $22 \%$ in adults aged $\geq 60$ years: a systematic review and meta-analysis. Br J Sports Med 2015;49:1262-1267.

20. US Department of Health and Human Services. 2008 Physical Activity Guidelines for Americans. http://health. gov/paguidelines/pdf/paguide.pdf Accessed March 16, 2016.

21. Blackwell DL, Lucas JW, Clarke TC. Summary health statistics for U.S. adults: National Health Interview Survey, 2012. National Center for Health Statistics. Vital Health Stat 10 2014;10:1-162.

22. Brown DR, Yore MM, Ham SA, Macera CA. Physical activity among adults $\geq 50 \mathrm{yr}$ with and without disabilities, BRFSS 2001. Med Sci Sports Exerc 2005;37:620-629.

23. Barnes PM, Schoenborn CA. Physical activity among adults: United States, 2000. Advance Data from Vital and Health Statistics. CDC Natl Center Health Stat 2003; 333:15.
24. Wang F, McDonald T, Reffitt B, Edington DW. BMI, physical activity, and health care utilization/costs among Medicare retirees. Obes Res 2005;13:1450-1457.

25. Martinson BC, Crain AL, Pronk NP, O'Connor PJ, Maciosek MV. Changes in physical activity and short-term changes in health care charges: a prospective cohort study of older adults. Prev Med 2003;37:319-326.

26. Nguyen HQ, Ackermann RT, Berke EM, et al. Impact of a managed-Medicare physical activity benefit on health care utilization and costs in older adults with diabetes. Diabetes Care 2007;30:43-48.

27. Nguyen HQ, Ackermann RT, Maciejewski M, et al. ManagedMedicare health club benefit and reduced health care costs among older adults. Prev Chronic Dis 2008:5:A14.

28. Woolcott JC, Ashe MC, Miller WC, Shi P, Marra CA, PACC Research Team. Does physical activity reduce seniors' need for healthcare?: A study of 24,281 Canadians. Br J Sports Med 2010;44:902-904.

29. Martin P, Kelly N, Kahana B, et al. Defining successful aging: a tangible or elusive concept? Gerontologist 2015; $55: 14-25$.

30. Ortman JM, Velkoff VA, Hogan H. An Aging Nation: The Older Population in the United States, 2014. www.census. gov/prod/2014pubs/p25-1140.pdf Accessed April 22, 2016.

31. AARP. Part 1. Chronic Conditions among Older Americans. 2009. http://assets.aarp.org/rgcenter/health/beyond_50_hcr_ conditions.pdf Accessed April 22, 2016.

32. Fries JF. Aging, natural death, and the compression of morbidity. N Engl J Med 1980;303:245-250.

33. Kaiser Family Foundation. MEDIGAP: Spotlight on Enrollment, Premiums, and Recent Trends. 2013. http:// kaiserfamilyfoundation.files.wordpress.com/2013/04/84122.pdf Accessed November 5, 2014.

34. Charlson ME, Pompei P, Ales KL, MacKenzie CR. A new method of classifying prognostic comorbidity in longitudinal studies: development and validation. J Chronic Dis1987;40:373-383.

35. Kroenke K, Spitzer RL, Williams JBW. The patient health questionnaire-2. Validity of a two-item depression screener. Med Care 2003;41:1284-1292.

36. Hughes ME, Waite LJ, Hawkley LC, Cacioppo JT. A short scale for measuring loneliness in large surveys. Res Aging 2004;26:655-672.

37. Wallace LS, Rogers ES, Roskos SE, Holiday DB, Weiss BD. Screening items to identify patients with limited health literacy skills. J Gen Intern Med 2006;21:874-877.

38. Fairies DE, Haro JM, Obenchain RL, Leon AC, eds. Analysis of observational healthcare data using SAS. Cary, NC: SAS Institute, Inc., 2010.

39. Seeger JD, Williams PL, Walker AM. An application of propensity score matching using claims data. Pharmacoepidemiol Drug Saf 2005;14:465-476.

40. Snyder A, Colvin B, Gammack JK. Pedometer use increases daily steps and functional status in older adults. J Am Med Dir Assoc 2011;12:590-594.

Address correspondence to: Shirley Musich, PhD Advanced Analytics Optum

315 E. Eisenhower Parkway, Suite 305 Ann Arbor, MI 48108

E-mail: shirley.musich@optum.com 